\title{
Psychosocial dimensions of early-onset puberty and its treatment
}

\author{
Celia Roberts \\ Lancaster University \\ 2016
}

Published in The Lancet, Volume 4, No. 3, p195-197, March 2016

http://www.thelancet.com/journals/landia/article/PIIS2213-8587(16)00038-3/abstract

Medical journals and popular media present early-onset puberty as a source of substantial parental, medical, and social concern-even a crisis. An article written by parents and a related editorial commentary in Archives of Disease in Childhood, ${ }^{1}$ for example, describe the condition as "devastating" and "frightening", and suggest that clinicians often fail to adequately support affected families. News media and science journalists similarly describe parents struggling to come to terms with their child's early sexual development, ${ }^{2}$ arguing that early-onset puberty entails a disturbing loss of innocence. ${ }^{3}$ Even publications from health activists ${ }^{4}$ suggests that parents feel "alarm, distress, distaste, guilt, and confusion". In each case, early-onset puberty is associated with a tragic diminution of childhood, a difficult-to-manage mismatch between physical bodies and psychosocial position, and a disturbing and untimely initiation of teenage sexuality. ${ }^{5}$

Psychological findings echo these concerns, showing that girls with early-onset puberty are more likely than their peers to enter into sexual relationships with older boys at a young age, to experience more psychological distress during their early teens, and to engage in risk-taking behaviours such as drug and alcohol consumption. 6 Johansson and Ritzén ${ }^{7}$ also showed lower educational achievement of girls with early-onset puberty during their teenage years and beyond, but they connected these differences to relationships with older boys rather than to early puberty per se.

As Graber and colleagues ${ }^{6}$ note, research into the psychosocial effects of early-onset puberty is confounded by additional findings that girls with the condition are more likely to have encountered challenging life experiences, such as racism, poverty, familial conflict, abuse, and disrupted care. In other words, the sexual behaviour, drug consumption, and low educational attainment of these girls might relate more directly to their personal and social contexts than to their developmental stage or pace. Disarticulation of physical, psychological, and social life events is conceptually and methodologically challenging: associations between life events and the timing of sexual development might be best addressed by open-ended qualitative research that attempts to explore connections rather than to produce categorical differentiations.

Early-onset puberty is, in some ways, highly treatable: gonadotropin-releasing hormone $(\mathrm{GnRH})$ analogues effectively halt sexual development, although the outcomes of such treatment are still not well understood. ${ }^{8}$ Many studies have explored these drugs' effects on adult height, with some results suggesting that timely treatment can increase height, whereas others showed little discernible effect. However, these outcome studies do not typically assess children's quality of life or psychosocial wellbeing. Descriptions of the 
benefits of $\mathrm{GnRH}$ analogues usually rely on logical rather than evidence-based justifications-i.e., if early development is linked to early sexuality, then delaying puberty will delay sexual initiation. Long-term studies of early-onset puberty treatments should assess psychosocial wellbeing and quality of life alongside physical outcomes such as bone density, cancer risk, and reproductive health.

Serious questions also remain concerning the timing and goals of treatment. When is puberty onset early enough to necessitate treatment? ${ }^{9}$ Is parental and child distress about early development best addressed through GnRH analogues? Is it desirable to use hormonal drugs to try to shape young peoples' sexual and risk-taking behaviours, and possibly their educational outcomes? As the authors of a report from the Child Growth Foundation ${ }^{4}$ note, medical prevention of puberty is no guarantee that a child's feelings or behaviour will change. Arguably, social support for individuals and families, improved sex and drug education, and wider cultural change in our understanding of childhood are more direct, appropriate, and potentially more effective routes to help young people to make life decisions and to facilitate parental care.

Medical assessment and treatment of children's sexual development might also trigger fear and shame, ${ }^{10}$ and can have enduring effects on an individual's sense of self and psychological wellbeing. Although these treatments aim to prevent psychological distress, they might actually produce it. As Kaplowitz writes in hisparental guide, ${ }^{11}$ "parents who have a generally healthy and happy 7-to-9 year old with early puberty should give serious thought to how the child might react to monthly shots and visits to the specialist for a physical exam, including breast measurement and blood tests, every three to four months." More in-depth research is needed to explore this issue.

Framing early-onset puberty as a crisis might ultimately hinder, rather than aid, attempts to address young people's and their parents' fears about premature sexual development and wider cultural concerns about changes to contemporary childhood. Additional research into the short-term and long-term psychosocial and physical outcomes of existing treatments and approaches, including in-depth qualitative analyses of children's and parents' experiences, is much needed.

\section{References}

1. O'Sullivan E, O'Sullivan M. Precocious puberty: a parent's perspective. Arch Dis Child 2002; 86: 320-21

2. Courtenay-Smith N. The girls who started going through puberty at THREE. Mail Online. Jan 13, 2008. http://www.dailymail.co.uk/femail/article-508020/The-girlsstarted-going-puberty-THREE.html (accessed Jan4, 2014).

3. Lemonick MD. Teens before their time. Time. Oct 30, 2000. http://www. time.com/time/magazine/article/0,9171,998347-3,00.html (accessed Jan 4, 2014).

4. Fry V, Stanhope R. Premature sexual maturation (including precocious puberty). London: Child Growth Foundation, 2004. http://www.childgrowthfoundation.org/CMS/FILES/04_Premature_Sexual_ Maturation.pdf (accessed Sept 15, 2014).

5. Roberts C. Puberty in crisis: the sociology of early sexual development. Cambridge: Cambridge University Press, 2015. 
6. Graber JA, Nichols TR, Brooks-Gunn J. Putting pubertal timing in developmental context: implications for prevention. Dev Psychobiol 2010; 52: 254-62.

7. Johansson T, Ritzén EM. Very long-term follow-up of girls with early and late menarche. Endocr Dev 2005; 8: 126-36.

8. Carel J-C, Eugster EA, Rogol A, et al. Consensus statement on the use of gonadotropin-releasing hormone analogs in children. Pediatrics 2009; 123: e752-62.

9. Kaplowitz P, Bloch C, Section on Endocrinology. Evaluation and referral of children with signs of early puberty. Pediatrics 2015; published online Dec 14. DOI: 0.1542/peds.2015-3732.

10. Baumann D, Landolt M, Wetterwald R, Dubuis J, Sizonenko P, Werder E. Psychological evaluation of young women after medical treatment for central precocious puberty. Horm Res 2001; 56: 45-50.

11. Kaplowitz P. Early puberty in girls: the essential guide to coping with this common problem. New York: Ballantine Books, 2004.

\section{Celia Roberts}

Centre for Gender and Women's Studies, and Department of Sociology, University of Lancaster, LA1 4YN, UK

celia.roberts@lancaster.ac.uk

This work was supported by a grant from the European Research Council. 